\title{
Programa Bela Praia ${ }^{1}$
}

\section{Bela Praia Program}

DOI: $10.46814 / \operatorname{lajdv3n5-007}$

Recebimento dos originais: 01/07/2021

Aceitação para publicação: 31/08/2021

\section{Helton Wesley Gonzaga}

Aluno líder do grupo e estudante do $8^{\circ}$. Semestre do Curso de Comunicação Social - Jornalismo

Universidade Federal do Tocantins, Palmas, TO

E-mail: heltongonzaga@gmail.com.

\section{Eugenia Paula Meireles Machado}

Estudante do $8^{\circ}$. Semestre do Curso de Comunicação Social - Jornalismo

Universidade Federal do Tocantins, Palmas, TO

E-mail: eugeniapaulam@gmail.com.

\section{Edinaldo Learte Viana}

Estudante do $8^{\circ}$. Semestre do Curso de Comunicação Social - Jornalismo

Universidade Federal do Tocantins, Palmas, TO

E-mail: edinaldo_viana@hotmail.com.

Wilma Araujo Modesto

Estudante do $8^{\circ}$. Semestre do Curso de Comunicação Social - Jornalismo

Universidade Federal do Tocantins, Palmas, TO

E-mail: wilma_rox@ hotmail.com.

\section{Liana Vidigal Rocha}

Orientadora do trabalho. Professora do Curso de Comunicação Social - Jornalismo,

Universidade Federal do Tocantins, Palmas, TO

E-mail: lianavidigal@yahoo.com.br.

\section{RESUMO}

Pautado na intenção de dar voz ao cidadão e exercer o direito constitucional e democrático da livre comunicação este projeto busca criar um programa de rádio voltado para a comunidade da Região Noroeste de Palmas, conhecida como ARNOS. Desenvolvido nos moldes de um programa de rádio comunitária, o Programa Bela Praia se propõe a ser um instrumento de valorização e difusão da cultura local ao respeitar os costumes, gêneros e a cultura dos moradores locais. Com uma linguagem simples, clara e ampla o programa traz informações de turismo, segurança, saúde, desenvolvimento local, dentre outros. A comunidade está inserida na construção e na continuidade deste projeto que fortalecerá os laços sociais, econômicos e culturais da região das ARNOS.

Palavras-chave: ARNOS, rádio, entrevista, comunicação, comunidade.

\section{ABSTRACT}

Based on the intention of giving voice to the citizen and exercising the constitutional and democratic right of free communication, this project seeks to create a radio program aimed at the community of the Northwest Region of Palmas, known as ARNOS. Developed in the molds of a community radio 
program, the Bela Praia Program proposes to be an instrument of valorization and diffusion of local culture by respecting the customs, genres and culture of the local residents. With a simple, clear, and broad language, the program brings information about tourism, security, health, local development, among others. The community is inserted in the construction and continuity of this project that will strengthen the social, economic, and cultural ties of the ARNOS region.

Key words: ARNOS, radio, interview, communication, community.

\section{INTRODUÇÃO}

Este trabalho tem como meta a criação de um programa radiofônico voltado para comunidade da Região Noroeste de Palmas, conhecida como ARNOS. A comunidade se destaca por suas características específicas quanto aos costumes, gêneros e cultura de seus moradores. A proposta prevê a distribuição do programa por um sistema de rádio comunitária, tendo como foco principal os frequentadores da Praia das ARNOS, centro de lazer e convivência dos moradores locais.

O Programa Rádio Bela Praia apresenta conteúdos variados. A programação conta com entrevistas de moradores e pessoas públicas que possam trazer ideias e soluções viáveis para a melhoria e o desenvolvimento da comunidade. São permitidas ainda, nos intervalos culturais do programa, propagandas do comércio local, em forma de apoiocultural (como orienta a legislação que rege as rádios comunitárias no Brasil), promoções, debates, enquetes e sorteio de brindes para a valorização de todos os moradores e do comércio da região.

A proposta firma-se a partir de uma necessidade prática, oriunda da constatação da inexistência de um canal de comunicação, de um programa que interage com todos os pontos ARNOS de uma forma ampla, simples, divertida, acessível e conveniente.

A região das ARNOS é uma das mais antigas da Capital tocantinense. Algumas de suas áreas são remanescentes de ocupações irregulares, outras até hoje se encontram nesta situação. Sua estrutura organizacional ainda tem deficiência em algumas áreas como sindicatos e associações, que possam de fato, trabalhar para o desenvolvimento direto da Comunidade.

A proposta busca unir forças através do empenho da comunidade e do comércio local e mostrar que a mídia e a propaganda podem trazer inúmeros benéficos a toda Regiãoa um custo acessível e simples principalmente.

Primeiramente, o público alvo são os moradores das ARNOS (todas as faixas etárias) que buscam lazer com qualidade, segurança, acessibilidade e acima de tudo informação com conteúdo variado, que fale da sua comunidade e na sua "língua".

Para isso é utilizada a Praia das ARNOS, com um forte potencial ecoturístico, o local é um dos atrativos turísticos mais conhecidos da cidade e ponto de encontro e lazerdos moradores da 
região. A busca por esse tipo de serviço vem aumentando consideravelmente, já que a Capital do Estado é conhecida também como uma capital ecológica.

O Programa Bela Praia busca ser um agente de apoio na consolidação da identidade cultural dos moradores das ARNOS. A gama de serviços e o comércio local também serão aquecidos internamente através das propagandas e promoções que terão o apoio e a divulgação no programa.

Como locais com potencial de possível concorrentes nesta proposta de ação e de transmissão radiofônica de baixa frequência, temos a Praia da Graciosa (Região Central da cidade, localizada na saída para o município de Paraíso), a Praia do Prata (localizada no seguimento da Avenida Teotônio Segurado) e a Praia do Caju, (localizada também no seguimento da Avenida Teotônio Segurado), entretanto todas elas possuem público segmentado e bastante diferente nos aspectos econômicos, sociais e culturais, fato que não irá interferir na proposta e na audiência do programa.

A escolha de um programa radiofônico em Rádio Comunitária dá-se por princípios básicos: o rádio é um veículo de comunicação de baixo custo de operacionalização e de grande abrangência. Outro ponto de destaque é a relação intrínseca entre os objetos deste projeto e a ideologia de ação das rádios comunitárias.

O rádio é um dos mais antigos meios de comunicação. Com uma grande abrangência no segmento de veículo de massa, o rádio se faz presente no cotidiano de muitas pessoas. Sua estrutura passou por várias modificações, mas sempre figurando na história da comunicação.

Em seu artigo intitulado “A participação nas rádios comunitárias no Brasil”, (1998; pag. 113), Cicília M. Krohling Peruzzo vem a endossar esta afirmação. A autora cita que as rádios comunitárias têm conseguido altos índices de audiência e de aceitação pelas comunidades. Este sucesso faz-se pela produção de uma programação sintonizada com os interesses, cultura e problemática local, aliado a uma proposta de inovação de programas e linguagens, que diferencia a rádio comunitária das demais rádios comerciais.

Outro ponto defendido por Peruzzo para o sucesso das rádios comunitárias, que por sua vez vem ao encontro das ideias do Programa Bela Praia, é o grande potencial de atrairos anunciantes locais, por conseguinte movimentando a economia local, tanto pelos preços mais baixos de suas inserções, quanto pelas possibilidades da alta segmentação de mercado, atingindo diretamente o público-alvo dos comerciantes das ARNOS, os moradores locais. Em suma, a proposta do Programa Bela Praia está intrinsecamente ligada à proposta de umarádio comunitária que é dar voz ao cidadão.

A melhor época para o início dos trabalhos do Programa Bela Praia é no período de férias, que traz mais turistas para a Praia das ARNOS, além do aumento do fluxo de 
moradores locais que procuram ambientes descontraídos para aproveitar seus dias de descanso. Assim o início da veiculação do programa estaria previsto para os meses de novembro e dezembro do ano de 2011.

Poderemos apresentar ao longo da implantação do projeto, pesquisas realizadas com os moradores da região para apurar os gostos e os hábitos das famílias que constituem a nossa audiência/público e estar apresentando resultados mais significativos a partir darecepção desses dados.

\section{OBJETIVO}

\subsection{GERAL}

Produzir e realizar um programa de rádio comunitária com informações, dicas de saúde, entrevistas e utilidade pública voltada, aos moradores da Região Norte de Palmas, possibilitando fomentar a convivência sociocultural.

\subsection{ESPECÍFICOS}

$1^{\circ}$ - Valorizar por meio de um programa de rádio, a cultura e identidade local dos moradores da praia das ARNOS e região.

$2^{\circ}$ - Incentivar a convivência e o desenvolvimento por meio local do programa radiofônico comunitário, Programa Bela Praia.

$3^{\circ}$ - Fazer do Programa Bela Praia um instrumento para a construção de uma cultura democrática, onde o cidadão reconheça e exerça sua força motivadora e receptora dos benefícios oriundos do relacionamento entre a radiodifusão local e o desenvolvimentocomunitário.

\section{JUSTIFICATIVA}

Com o advento da globalização, a sociedade passa pelas mais diversas transformações no que se refere à formação pessoal dos indivíduos e, consequentemente,

afasta-se das práticas inerentes a sua cultura e aos poucos, perdendo o vínculo com o seu meio comunitário.

$\mathrm{Na}$ medida em que perdem sua identidade esses indivíduos necessitam de uma pontede interação que os liguem às suas raízes culturais. Por isso, apresentamos este programa deradiodifusão que busca a participação popular deste público que constantemente é bombardeado pela grande mídia 
local com informações que valorizam o turismo de outras praias e balneários, e não daquela região. O projeto será conduzido por acadêmicos de comunicação social da Universidade Federal do Tocantins (UFT) e orientados pela professora Liana Vidigal das disciplinas de Projeto Experimental I e II.

Outro ponto preponderante da escolha do rádio neste projeto é a portabilidade do equipamento. Muitas pessoas ouvem a programação do rádio dentro dos carros, ônibus e atémesmo através dos aparelhos celulares. A própria pesquisa realizada antes da apresentação desta proposta aponta que grande parte dos entrevistados ouve rádio diariamente. Diante de todas estas explanações chega-se a conclusão que o rádio se torna o veículo de comunicação mais apropriado para a proposta.

Por outro lado, a escolha do modelo de rádio comunitária fez-se diante da ligação ideológica do projeto com este modelo de radiodifusão. A intenção de trazer a comunidade para as discussões, para a produção do programa e informá-la de assuntos de seu interesse está umbilicalmente ligada à ideologia das rádios comunitárias.

Este projeto de programa de rádio é voltado para a comunidade local da região das ARNOS e busca, em princípio, elaborar um estudo que venha colaborar com a expansão, valorização cultural e a autoestima dos frequentadores da Praia das ARNOS.

O intuito é de valorizar e fortalecer a identidade cultural dos banhistas através de umproduto de comunicação radiofônica que mescle, em sua programação, quadros que abordem os assuntos pertinentes a informações educativas, de saúde, culturais. A participação da comunidade será feita através de entrevistas e enquetes, que venham acrescentar de forma direta e indireta o intuito de dar voz a comunidade local, respeitando

as diversidades de opiniões necessárias para o exercício da cidadania tendo como balizadora democracia.

O acadêmico ao produzir e conduzir este projeto terá a oportunidade de vivenciar o cotidiano do radiojornalismo e atuar na produção e execução de um programa voltado para os interesses de uma comunidade específica. Outro ponto a ser ressaltado é que as notícias serão totalmente voltadas e produzidas para a conscientização do público-alvo sobre os direitos do cidadão, os cuidados com a saúde e maneiras de prevenir doenças que são propícias no verão.

\section{MÉTODOS E TÉCNICAS UTILIZADOS}

A proposta do Programa Bela Praia surgiu após a constatação da inexistência de um canal de comunicação local, que valorize os aspectos socioculturais e econômicos dos moradores da Região Noroeste de Palmas (ARNOS). O programa foi desenvolvido dentro dos moldes dos programas para Rádios Comunitárias, estando apto para sua veiculação neste sistema de radiodifusão. 
O público-alvo deste projeto são os frequentadores da Praia das ARNOS e osmoradores da Região. A escolha das entrevistas e demais informes do Programa Bela Praia foram projetados a partir de uma pesquisa de demanda, das necessidades e dos gostos dos moradores da Região das ARNOS. O estudo de campo, realizado junto à comunidade local em março de 2011(amostragem aleatória com 100 pessoas, moradores e frequentadores da praia das ARNOS e região), possibilitou traçar todas estas características que serão constantemente revistas através de pesquisas de audiência, de consultas populares e enquetes realizadas no próprio desenrolar do programa.

O projeto é desenvolvido pelos acadêmicos do Curso de Comunicação Social - Jornalismo da Universidade Federal do Tocantins, sob a orientação da professora doutora Liana Vidigal Rocha. Os acadêmicos são responsáveis pela apresentação do programa, bem como pela realização das entrevistas, produção e finalização do material.

Foi utilizada a estrutura do laboratório de rádio da instituição de ensino e equipamentos próprios para as entrevistas e finalização do material. O material foi totalmente editado pelo grupo.

\section{DESCRIÇÃO DO PRODUTO OU PROCESSO}

O programa radiofônico Bela Praia será apresentado primeiramente, aos sábados, podendo ser ampliado para o domingo também, com a duração média de 15 minutos, dividido em quadros voltados para as necessidades da comunidade.

O programa conta com três locutores responsáveis pela apresentação do programa no estúdio: Helton Gonzaga; Edinaldo Viana e Eugenia Meireles e dois repórteres: Wilma Araujo e Helton Gonzaga, que se dividem entre o estúdio, a praia das ARNOS e as quadras circunvizinhas e realizam entrevistas, e boletins com dicas de saúde e utilidade pública. O programa apresenta uma linguagem simples e dinâmica para a compreensão do público alvo.

As vinhetas de abertura, do decorrer do programa e as de encerramento têm aproximadamente cinco segundos de duração. As vinhetas recebem um tratamento elaborado em estúdio, mas sem perder a característica de um programa voltado para a comunidade. Ao final se terá um produto totalmente pronto para exposição e veiculação.

\section{Quadros do Programa:}

- Bela Turismo: Informações e sugestões sobre turismo local, diversão e lazer na Região das ARNOS e nas demais regiões da Capital.

- Bela Segurança: Quadro elaborado com a presença de um bombeiro, policial e demais autoridades que possam indicar normas e dicas de segurança, bem como procedimentos de 
primeiros socorros e sugestões para banhistas e pais com crianças.

- Bela Saúde: Entrevista feita com um profissional de saúde onde serão abordados temas relacionados à prevenção de doenças, cuidados com corpo e algumas respostas paras as principais dúvidas da comunidade.

- Papo Cidadão: Quadro de entrevista com um morador responsável pela voz da comunidade, moradores antigos, presidentes de associação de moradores e demais pessoas influentes que desenvolvam um trabalho relevante para o crescimento local. Um bate-papo onde serão colocadas as necessidades da comunidade, a realidade eos projetos que fazem a diferença na Região das ARNOS.

\section{CONSIDERAÇÕES}

O projeto do Programa Bela Praia possibilitou a vivência entre os conceitos teóricos sobre radiojornalismo, jornalismo comunitário, critérios de noticiabilidade e a construçãoda notícia, com o dia-a-dia de uma produção radiofônica e os entraves da produção de um radiojornal. A execução do projeto foi uma oportunidade ímpar para se colocar em prática estes conceitos teóricos e avaliar a sua importância no produto final.

A justificativa deste projeto também foi colocada à prova e comprovada a necessidade de um programa que viesse a fortalecer os laços sociais e culturais dos moradores da Região Noroeste de Palmas, ARNOS, com uma linguagem própria, clara e ampla. Outra constatação positiva, diante da proposta colocada, foi a aceitação do projeto e o apoio dos agentes comunitários envolvidos desde a pesquisa, coleta de dados e entrevistas.

O Programa Bela Praia, além de fortalecer o ambiente social e cultural dos moradores das ARNOS, também se mostrou um forte instrumento de informação, com uma ampla abrangência na comunidade. O conteúdo veiculado busca ir ao encontro das necessidades de informação levantadas durante a pesquisa. De forma simples, clara eobjetiva as informações de utilidade pública, saúde, segurança, dentre outras são repassadasaos ouvintes.

No campo econômico o projeto se mostrou capaz de aquecer o comércio local efazer frente aos grandes comércios de Palmas, que fazem a divulgação de seus produtos na grande mídia. $\mathrm{Na}$ forma de apoio cultural, os comerciantes locais têm um espaço para divulgar seus produtos diretamente na sua comunidade, levando sua proposta ao seu público alvo. Para não quebrar a confiança dos comerciantes locais e nem favorecer nenhum estabelecimento não foi veiculado neste projeto os intervalos comerciais na forma de apoio cultural, como rege a legislação das rádios comunitárias, visto que não há espaço para veiculação de todos neste piloto. 
Por fim o Programa Bela Praia se mostrou um projeto sustentável, um produto pronto para ser veiculado em uma rádio comunitária local, com condições de ser mantida sua veiculação semanal. 


\section{REFERÊNCIAS BIBLIOGRÁFICAS \\ REFERÊNCIAS BIBLIOGRÁFICAS}

BEZERRA JÚNIOR, Wilton. Rádio: do amadorismo ao profissionalismo. UFC, 1995 GRUPODE MONOGRAFIA.O Rádioe suas contribuiçõespedagógicasno processoeducacional.Em:

<http://anlyteo.blogspot.com/2007/09/o-rdio-e-suas-contribuies-pedaggicas-no.html> Acesso em: 23 de Janeiro de 2012.

MINISTÉRIO DAS COMUNICAÇÕES. 〈wwww.mc.gov.br〉 . Acesso em: 26 de Janeiro de2012.

PERUZZO, Cicilia M. Krohling. Comunicação nos Movimentos Populares: A Participação na Construção da Cidadânia. Petropólis (RJ): Vozes, 1998.

PERUZZO, Cicilia M. Krohling. Participação nas Rádios Comunitárias no Brasil. In: XXI Congresso Brasileiro de Ciências da Comunicação. Recife-PE, 9 a 14 de Setembro de1998. (Artigo apresentado no GT Cultura e Comunicação Popular).

PORCHAT, Maria Elisa. Manual de Radiojornalismo Jovem Pan. São Paulo: Ática,1993.

PRADO, Emílio. Estrutura da informação radiofônica. Trad. Mauro Antônio deCarvalho, São Paulo: Summus, 1989.

SÁ, Adísia. Viagem ao redor do rádio, Guia do rádio \& televisão 2008. [S.I.]: Acert,2008. 